Gut, 1987, 28, S1, 237-241

\title{
Growth and differentiation of intestinal endodermal cells in a coculture system
}

\author{
M KEDINGER, P SIMON-ASSMANN, AND K HAFFEN \\ From INSERM, Unité 61, Biologie Cellulaire et Physiopathologie Digestives, Strasbourg, France
}

SUMMARY To investigate the role of epithelial-mesenchymal interactions on intestinal maturation, we cultured embryonic epithelial cells in several experimental conditions. Microexplants of 14-15 days fetal rat intestinal endoderm, separated from the mesenchyme by collagenase, were seeded on dishes coated with different extracellular matrix components (collagens I, III, IV, fibronectin, laminin) or on confluent monolayers of intestinal mesenchymal cells or of fetal skin fibroblasts. Only small variations in the attachment or spreading of the endodermal cells could be observed when they were cultured on the different substrata and their survival never exceeded one week. When cocultured with intestinal or skin fibroblasts, however, endodermal cells grew, formed a monolayer, survival time was prolonged up to two to three weeks, and differentiation occurred. This differentiation was assessed by cell polarisation, morphological maturation of apical brush borders, synthesis of microvillar digestive enzymes and of extracellular matrix molecules seen immunocytochemically. Finally, glucocorticoids which are known to stimulate or induce brush border enzymes, accelerated the morphological and enzymatic maturation only in the cocultures.

The developing intestine provides an excellent system to investigate the tissular and hormonal regulation of epithelial differentiation. The morphological polarisation as well as the expression of digestive enzymes represent specific phenotypic and molecular markers of intestinal epithelial differentiation. There is substantial evidence that the enzymatic maturation is under control of hormones (especially glucocorticoids in rodents) and that interactions between epithelial cells and the underlying connective tissue are involved in the processes of intestinal morphogenesis and differentiation. ${ }^{12}$ Such evidence is supplied by microscopical observations of cell contacts ${ }^{3}$ and by several experimental models of tissular associations. ${ }^{124}$ In addition, the observation of changes in the distribution of extracellular matrix (ECM) components during intestinal development ${ }^{5}$ raises the question whether tissular interactions could act via some of these molecules. Such an assumption has already been reported in several cell types. ${ }^{6}$ Moreover, acquiring hormone sensitivity by different epithelia seems to be dependent upon cell interactions via direct contacts ${ }^{7}$ or specific substances secreted by mesenchymal cells. ${ }^{8}$ The fact that intestinal epithelial cell lines do

Address for correspondence: Dr M Kedinger, INSERM U61, Biol. Cell et Physiopath. Digest, 3 Avenue Molière, 67200 Strasbourg, France not express differentiated phenotypes ${ }^{9}$ and that primary cultures rapidly lose their differentiation potential, ${ }^{10}$ led us to design an in vitro model system in which we could modulate various cellular and hormonal parameters in defined experimental conditions.

We analysed (a) the possible growth and differentiation promoting activity of ECM components and of mesenchyme derived cells, for endodermal cells (fetal intestinal epithelial cells), and (b) the possible involvement of mesenchymal cells in the response of the endodermal cells to glucocorticoids. We found that unlike ECM components, direct contacts with mesenchymal cells provide a positive support for differentiation of endodermal cells in vitro and for their response to glucocorticoids. Further data suggest that these hormonal effects could include an inhibition of fibroblastic proliferative activity.

\section{Methods}

MATERIALS

Culture conditions

The endoderm of rat fetal intestines (14 or 15 days) were separated from the surrounding mesenchyme (future connective tissue and muscular layers) by 
collagenase treatment $(0.03 \%$, one hour). Microexplants of pure endoderms were seeded on matrix coated dishes or on top of confluent fibroblastic cultures.

\section{Extracellular matrix substrates}

The proteins used for coating included collagens type I, type IV, procollagen type III, fibronectin or laminin at concentrations comprised between 5 and $10 \mu \mathrm{g} /$ $\mathrm{cm}^{2}$ (generous gifts from Dr U Kühl: Max Planck Institut für Biochemie, Martinsried bei München). Fibroblast-derived matrices have been obtained by treatment of confluent cultures with Triton X 100 $(0.5 \%)$, with a mixture of enzymes $(0.1 \%$ trypsin, $0.1 \%$ pancreatin, $0.4 \%$ EGTA) or by hypotonic shock.

\section{Cellular substrates}

Fibroblastic cultures originating either from 14 days fetal rat intestinal mesenchyme or from 20 days fetal rat $\operatorname{skin}^{11}$ were used at confluency after one to four passages as support for endodermal cells.

\section{Culture medium}

The basic culture medium used was composed of $\mathrm{MEM} / \mathrm{HamF}_{12}$ (1:1) enriched with $7.5 \%$ fetal calf serum containing $2.5 \%$ serXtend serum substitute (NEN). In some experiments, dexamethasone $\left(\mathrm{DX} ; 10^{-7} \mathrm{M}\right)$ or fibroblast conditioned medium $(50 \% ; \pm \mathrm{DX})$ were added.

\section{PROCESSING FOR ELECTRON MICROSCOPY}

After primary fixation in $2 \%$ glutaraldehyde in a $0.2 \mathrm{M}$ cacodylate buffer $\mathrm{pH} 7 \cdot 4$, the cells cultured in the different experimental conditions were treated by conventional methods for scanning (SEM) and transmission (TEM) electron microscopical analysis. ${ }^{11}$

\section{IMMUNOCYTOCHEMICAL LOCALISATION OF BRUSH BORDER ENZYMES AND OF ECM PROTEINS}

The expression of digestive enzymes at the microvillar level has been revealed by immunofluorescent labelling by means of monoclonal antibodies against sucrase-isomaltase, maltase-glucoamylase, lactase, aminopeptidase and alkaline phosphatase, kindly provided by Drs H P Hauri (Biocenter, Basel) ${ }^{12}$ and A Quaroni (Cornell University, Ithaca, NY) ${ }^{13}$ Cells cultured on glass coverslips were fixed and prepared according to methods previously detailed. ${ }^{11}$

Synthesis of matrix components (type I and IV collagens, laminin, nidogen, fibronectin, type III procollagen) has been assessed immunocytochemically on unfixed cryosectioned cell sheets ${ }^{5}$ with antibodies kindly supplied by Drs R Timpl and K
Von der Mark (Max Planck Institut für Biochemie, Martinsried bei München).

ANALYSIS OF FIBROBLASTIC CELL

PROLIFERATION

${ }^{3} \mathrm{H}$-thymidine $(1 \mu \mathrm{Ci} / \mathrm{ml}, \mathrm{SA}: 72 \mathrm{Ci} / \mathrm{mM})$ was added for 24 hours at different culture periods (seven, 10 and 14 days) in confluent fibroblastic monolayers cultured in the presence or absence of DX. Cells were trypsinised, counted and treated by successive precipitations with TCA for subsequent quantification of ${ }^{3} \mathrm{H}$-thymidine incorporation in macromolecules.

\section{Results}

\section{ENDODERMAL CELLS CULTURED ON ECM} SUBSTRATES

Endodermal microexplants cultured on plastic or on matrix coated dishes (type I collagen, type III procollagen, and fibronectin) did not display significantly different fates (attachment, spreading, survival). Eighty per cent of the endodermal explants attached to the dishes, spread within 24 hours approximately. Thereafter, in the control or coating conditions, the enlargement of the endodermal areas was very limited, reflecting a low rate of proliferation. After four to six days in culture the cells rapidly died. In contrast, laminin and type IV collagen coatings resulted in a pronounced suppression of attachment of the explants $(40 v 80 \%)$ and of the survival of the cells on collagen IV; laminin at the opposite allowed survival of attached cells up to seven days.

Despite their overall short survival, the cells underwent the start of morphological and enzymatic differentiation as assessed by their polarisation after four days in culture, in particular the presence of tight junctions, of rudimentary brush borders and by the positive immunolabelling of lactase and aminopeptidase of some cells scattered within the colony. Addition of dexamethasone into the culture medium did not modify the morphology, and brush border enzyme expression.

\section{ENDODERMAL CELLS CULTURED ON CELLULAR SUBSTRATES}

Attachment and spreading of endodermal microexplants seeded on the top of confluent monolayers of mesenchyme derived cells were similar to those described on untreated surfaces (Fig. 1a). Their subsequent behaviour was, however, different as assessed by the following criteria: promotion of epithelial cell proliferation, leading to a confluent monolayer overlying the fibroblasts, (Figs 1b, c) prolonged survival (up to two to three weeks), and 

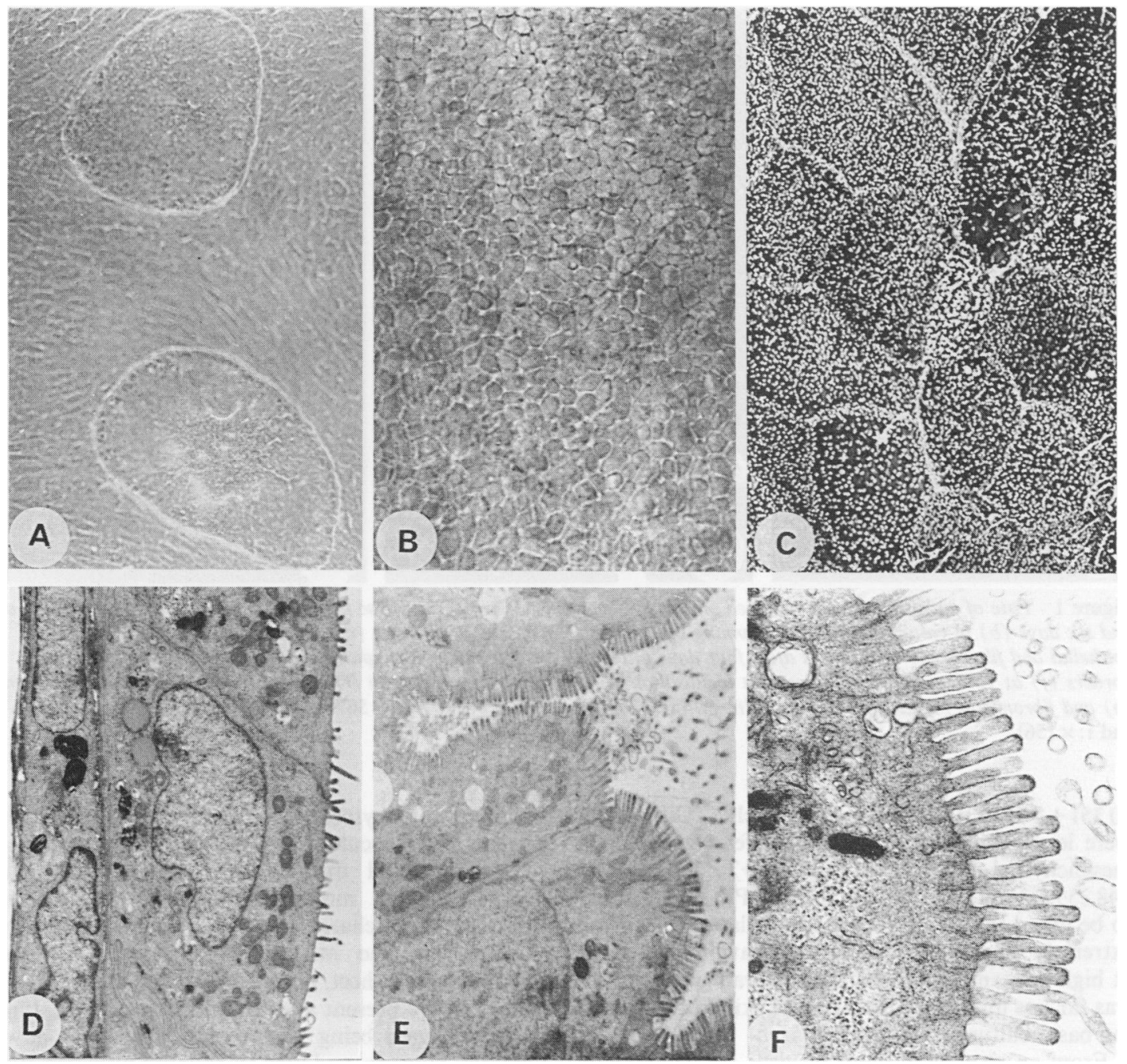

Fig. 1 For caption see p. 240.

progressively enhanced expression of enterocytic differentiation characteristics (Figs le, f). The addition of dexamethasone to the culture medium resulted, during the first week, in an acceleration of the morphological differentiation of the epithelial cells, leading to an increased number of maturing cells. Thereafter, glucocorticoids exerted a stabilising effect on them, resulting in an enhanced survival.

Concerning the epithelial mesenchymal interface, the following observations were of interest: at four days of culture a well delimited basal membrane separated the two cell types (Fig. 1d). At 10 days, direct membrane contacts between epithelial cell processes and fibroblasts could be seen, which were progressively replaced from 12 days onwards by an undulated electron dense material.

The underlying fibroblastic cells always exhibited elongated shapes parallel to the epithelial/mesenchymal interface (Fig. 1d). As revealed by phase contrast microscopy DX-supplemented medium modified the morphological appearance of the fibroblasts which became large and flattened. Therefore we analysed their proliferative activity in the presence and absence of DX. At confluency, the number of skin fibroblasts per dish as well as the rate of ${ }^{3} \mathrm{H}$-thymidine incorporation during 24 hour periods were drastically inhibited by DX: $10 \cdot 8 \pm 1 \cdot 4$ $v 5.5 \pm 0.7 \times 10^{5}$ cells and $197946 \pm 10868 v$ 

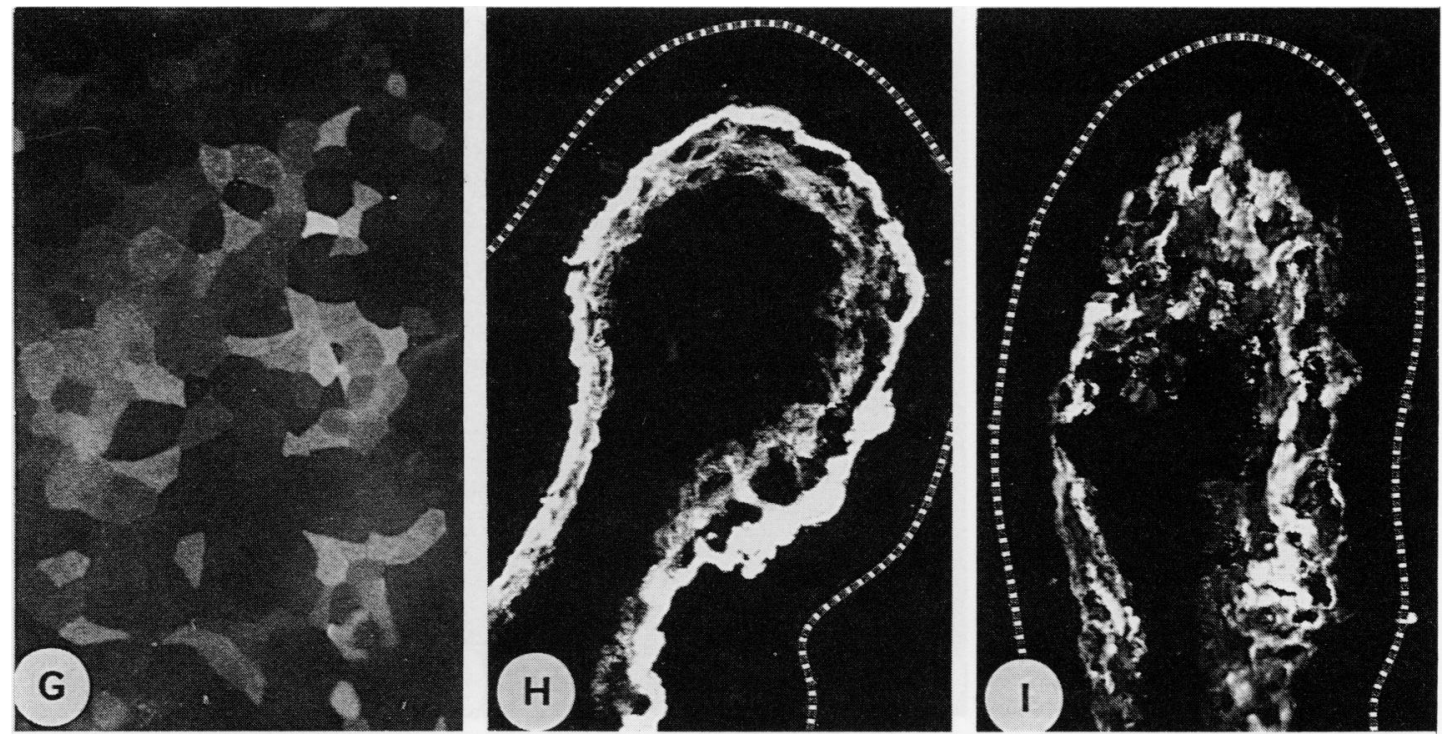

Figure 1 Fate of endodermal cells cultured on top of fibroblasts. View at the phase contrast microscope after 24 hours (a) and six days $(b)$ in culture, and at the scanning electron microscope after six days (c). Ultrastructural aspect of both epithelial and fibroblastic cell layers after four days in culture (d); details of the epithelial cells and of their apical brush borders $(f)$ at 12 days. Immunofluorescent localisation of lactase after four days in DX culture medium $(\mathrm{g})$ and of laminin (h) and fibronectin (i) in eight days cocultures. $(\mathrm{a}: \times 250, \mathrm{~b}: \times 750, \mathrm{c}: \times 1600, \mathrm{~d}: \times 5670, \mathrm{e}: \times 5184, \mathrm{f}: \times 11584, \mathrm{~g}: \times 220, \mathrm{~h}$ and $\mathrm{i}: \times 156$ ).

$40351 \pm 8553 \mathrm{DPM} /$ dish respectively. Differences were less significant in the case of fetal gut derived mesenchymal cells $\left(11 \cdot 2 \pm 1 \cdot 0 v 9 \cdot 5 \pm 0 \cdot 7 \times 10^{5}\right.$ cells and $148255 \pm 31322 v 118750 \pm 21138 \mathrm{DPM} /$ dish). It has to be noted that the growth of these latter cells being extremely density dependent, they have to be seeded at high concentration and their overall proliferation was far less important than that of skin fibroblasts in the basal culture conditions.

From an enzymatic point of view, we could show that in the absence of DX, microvillar digestive enzymes visualised immunocytochemically were expressed after four days in culture by numerous epithelial cells in the case of alkaline phosphatase and by a limited number of cells scattered within the monolayer in the case of maltase, lactase and aminopeptidase. In contrast, addition of DX to the culture medium enhanced significantly the number of immunolabelled cells (except for alkaline phosphatase) at a culture period of between four and six days (Fig. 1g). It also induced sucrase-isomaltase expression in several cells after six days in culture. Neither culturing the cells on fibroblast derived matrix nor culturing them with DX-conditioned medium enhanced proliferation and survival rate or induced responses to glucocorticoids similar to those observed in the coculture conditions.
The immunocytochemical analysis of ECM components in the cocultured epithelial and mesenchymal cells emphasised that in this model system the different matrix molecules were synthesised and exhibited their characteristic distribution patterns. Localised at the intercellular spaces within the fibroblastic cell sheet, fibronectin (Fig. 1h) and type I collagen were present after four days in culture, type III procollagen being visible only after eight days. Laminin, nidogen, and type IV collagen were detected at the epithelial/mesenchymal interface (Fig. 1i) after four days for the former and eight days for the others. Such a distribution pattern was as obvious in the presence as in the absence of DX, provided that both cell types are in contact.

Taken together, the data reported here emphasise: (1) that isolated ECM components were unable to replace fibroblastic cells in their potency to support intestinal endodermal cell proliferation and survival, (2) that in the coculture conditions and whatever the tissular origin of the mesenchyme derived cells, several enterocytic differentiation markers were expressed by the endodermal cells, (3) that the epithelial response to glucocorticoids was mediated by mesenchymal elements without tissular specificity and that this hormonal effect might include an inhibition of mesenchyme cell proliferation. 
We would like to thank E Alexandre and C Arnold for their skilful technical assistance, C Haffen for photographic processing and I Gillot for typing the manuscript. We are very grateful to Drs H P Hauri (Biocenter, Basel), A Quaroni (Cornell Univ. Ithaca, NY), R Timpl and $\mathrm{K}$ Van der Mark (Max-Planck Institut für Biochemie, München) for kindly providing the different antibodies.

\section{References}

1 Kedinger M, Haffen K, Simon-Assmann P. Control mechanisms in the ontogenesis of villus cells. In: Desnuelle P, Sjöström H, Norén O, eds. Molecular and cellular basis of digestion. New York: Elsevier, 1986: 315-26.

2 Haffen K, Kedinger M, Simon-Assmann P. Mesenchyme-dependent differentiation of epithelial progenitor cells in the gut. J Pediatr Gastroenterol Nutr 1986; 6: 14-23.

3 Mathan M, Hermos JA, Trier JS. Structural features of the epithelio-mesenchymal interface of rat duodenal mucosa during development. J Cell Biol 1972; 52: 57788.

4 Haffen K, Kedinger M, Lacroix B. Cytodifferentiation of the intestinal villus epithelium. In: Desnuelle $\mathbf{P}$, Sjöström H, Norén O, eds. Molecular and cellular basis of digestion. New York: Elsevier, 1986; 303-14.

5 Simon-Assmann $\mathbf{P}$, Kedinger M, Haffen K. Immunocytochemical localization of extracellular matrix proteins in relation to rat intestinal morphogenesis. Differen- tiation 1986; 32: 59-66.

6 Bissell MJ, Hall GH, Parry G. How does the extracellular matrix direct gene expression? $J$ Theor Biol 1982; 99: 31-68.

7 Levine JF, Stockdale FE. Cell-cell interactions promote mammary epithelial cell differentiation. J Cell Biol 1985; 100: $1415-22$.

8 Dow KE, Sabry K, Smith BT. Evidence for epithelialmesenchymal interactions mediating glucocorticoid effects in developing chick liver fibroblast-hepatocyte factor. Cell Tissue Res 1983; 231 : 83-91.

9 Quaroni A, May RJ. Establishment and characterisation of intestinal epithelial cell cultures. In: Harris CC, Trump BF, Stoner GD, eds. Methods in cell biology. New York: Academic Press, 1980; 21B: 403-27.

10 Quaroni A. Development of fetal rat intestine in organ and monolayer culture. J Cell Biol 1985; 100: 161122.

11 Kedinger M, Simon-Assmann P, Alexandre E, Haffen $K$. Importance of a fibroblastic support for in vitro differentiation of intestinal endodermal cells and for their response to glucocorticoids. Cell Differ 1987; 20: 171-82.

12 Hauri HP, Quaroni A, Isselbacher KJ. Monoclonal antibodies to sucrase/isomaltase; probes for the study of postnatal development and biogenesis of the intestinal microvillus membrane. Proc Natl Acad Sci USA 1980; 77: 6629-33.

13 Quaroni A. Use of monoclonal antibodies in the study of intestinal structure and function. Brush border membranes. Ciba Foundation Symposium, London: Pitman, $1983 ; 95: 113-31$. 